\title{
A Perda do Fio Narrativo SObre A INSUSTENTABILIDAdE DO TrágICO NA CONTEMPORANEIDADE
}

\author{
Teresa M.L.R. Cadete ${ }^{1}$
}

(Professora Catedrática, Faculdade de Letras, Universidade de Lisboa)

Ironicamente, poder-se-ia dizer que estamos perante uma tríade de pensadores que absorveram de forma trágica as contradições ao longo de um século (entre 1844, data do nascimento de Friedrich Nietzsche, e 1940, data da morte de Walter Benjamin), pautadas pela sombra experiencial de 3 guerras. Precisamente por isso, estes autores viram-se atravessados por e confrontados com problemáticas cuja dimensão paradoxal, simultaneamente necessária e insustentável, lhes era familiar. Se menciono aqui a guerra franco-prussiana e as duas guerras mundiais, não o faço com a intenção de sublinhar o evidente grau de violência patente nestes mega-conflitos, mas sobretudo com o fim de chamar a atenção para o carácter despoletador de conhecimento, bem como de expressão de monstruosos absurdos, dos mesmos.

Dito de outra maneira: se a violência, manifestação evidente em qualquer empreendimento bélico, é também constitutiva da tragédia, porém não o é menos uma combinação explosiva e paradoxal de necessidade e absurdidade. Isto por um lado. Por outro lado, todos os três autores cuja obra aqui se tematiza estavam manifestamente conscientes do grau de violência que se impregna em qualquer código cultural, podendo mesmo este ser um aspecto comum que atravessa todo o pensamento de Nietzsche, Simmel e Benjamin.

\footnotetext{
${ }^{1}$ trcadete@googlemail.com
}

Philosophica, 46, Lisboa, 2015, pp. 9-17. 
A dinâmica do trágico é assinalada já pelo jovem Nietzsche "enquanto os trovões da batalha de Wörth percorrem a Europa" (KSA 1, 11), como escreve o autor catorze anos depois da primeira publicação do Nascimento da Tragédia. Nesta sua primeira fase de vida e obra, Nietzsche ainda tenta equilibrar o impacto dionisíaco, que situamos sem hesitar no epicentro da tragédia, com a função conciliatória, esteticizante e balsamizante, do princípio apolíneo. É desse equilíbrio que poderia nascer um "pessimismo da força", uma "tentadora ousadia da mais arguta visão" (ib., 12), escreve ainda o autor ao distanciar-se de um texto que lamenta então ter tributado anteriormente, como cedência - que nesse prefácio posterior ele confessa não se perdoar a si próprio, ao negativismo schopenhaueriano e à megalomania wagneriana.

Uma constante permanecerá porém na obra de Nietzsche: o reconhecimento incondicional da lição grega acerca do trágico e da tragédia. A relação entre ambos poderia assemelhar-se à proporção entre ambiente e sistema ou, dito de outra maneira, a tragédia poderia ser vista como um núcleo, ocasionalmente detonado, de uma célula que o alimenta - o tecido trágico. Ocasionalmente, mas não sem uma relação de causalidade. Se o trágico palpita com o respirar do quotidiano cultural, a tragédia explode com o avolumar das condições de possibilidade que a ela conduzem. Daí podemos induzir que se não existe tragédia sem trágico, este pode - deve? - ser cultivado enquanto húmus, tecido e forma de "arguta visão" de que falava Nietzsche. Já décadas antes, no início do século XIX, no seu ensaio sobre o sublime, Friedrich Schiller defendera a acção "inoculadora" de uma consciência trágica proporcionada pela cultura, semelhante a uma vacina com o fim de prevenir ou minimizar os efeitos devastadores de uma real tragédia (cf. Schiller, 1997: 229).

No final da sua obra de 1888 Crepúsculo dos Ídolos, Nietzsche passa em revista tudo o que deve aos clássicos e que se poderia resumir numa forma de olhar para a dimensão trágica do real, sem abdicar da plena afirmação de uma "vontade incondicional de não criar qualquer ilusão e de ver razão na realidade, não num conceito normativo e restritivo de 'razão' e ainda menos na "moral'" (KSA 6, 156). Assim, a positividade desta leitura recorta-se na crítica ao que o autor considera fraudes metafísicas e soteriológicas, às heranças platoniana e cristã. Sem esta dobra crítica dificilmente se poderia entender a insistência nietzscheana numa plenitude que pressupõe não apenas uma tentativa de equilíbrio entre consciência e vitalidade, em mútuo reconhecimento, mas sobretudo a possibilidade de situar essa realidade no movimento do tempo, recuperando a História no sentido dessa "força plástica" (KSA 1, 251) autopoiética. Tal força possuiria, por assim dizer, uma narratividade regeneradora de que já testemunhava a segunda 
Intempestiva ao distanciar-se da grelha positivista da escola histórica. Neste sentido, Nietzsche vê em Tucídides "a última revelação dessa factualidade forte, severa, dura, que residia no instinto do mais antigo Heleno" (KSA 6, 156).

Podemos considerar tal caracterização como idealização de uma consciência cósmica, o que porém não nos impede de atribuir a essa mesma consciência uma capacidade trágica no seu compromisso com a temporalidade e a narratividade. Assim, o tecido trágico integra sem problemas qualquer leitura histórica enquanto fio narrativo que confere sentido ao absolutismo da tragédia e por aí o relativiza quando a mesma tragédia irrompe como resultado da cegueira, credulidade ou narcisismo dessa ou dessas figuras que devemos hesitar em chamar heróis, até porque acabam por ver submersa e anulada na avalanche trágica qualquer auto-ilusão de grandeza. $\mathrm{O}$ que a clarividência nietzscheana parece querer dizer-nos seria, na concisão das contemporâneas fórmulas anglo-saxónicas, que simplesmente life goes on e que a sustentabilidade das sequelas provocadas pelo desencadear da tragédia se revela melhor quando as mesmas são enfrentadas por uma consciência trágica, que por sua vez não pode deixar de ser o produto de um longo trabalho da cultura.

Como nos lembrou Jean-Marie Domenach, os espíritos mais fecundos e inesgotáveis não deixam de pagar um preço altíssimo por se terem instalado e permanecido no centro do trágico (Domenach, 1968: 29). Tal asserção é plenamente válida para Nietzsche e Benjamin, embora não tanto para Simmel. Este autor chama porém a atenção - quase poderíamos dizer nolens volens - para uma concepção de cultura que, saída do âmbito da especulação teórica para a arena político-mediática, contribuiu para adensar códigos mentais de fechamento ao que a realidade europeia exigia no ano de 1911 (data da publicação do seu ensaio sobre o conceito e a tragédia da cultura). Nesta óptica, poderíamos discernir uma mensagem profética na caracterização daquilo a que chamaria de explosividade da cultura. Escreve Simmel que a "fatalidade trágica (tragisches Verhängnis)" da cultura adviria do facto de as forças destrutivas, orientadas para um ser, brotariam das camadas mais profundas desse mesmo ser. Com tal destruição consumar-se-ia um destino que teria sido depositado nesse próprio ser e que seria o desenvolvimento lógico precisamente da estrutura com a qual o ser teria construído a sua positividade (cf. Simmel, 1986: 215). Com uma frieza laboratorial, Simmel antecipa a sétima tese benjaminiana sobre a inevitabilidade de um documento de cultura ser também um documento de barbárie. Mas lá chegaremos.

Se, como vimos, Nietzsche e Benjamin se situaram no centro nevrálgico do trágico e - por circunstâncias que nos são conhecidas e 
não é necessário aqui aprofundar - não puderam subtrair-se ao mesmo para observar à distância o desencadear da respectiva tragédia pessoal, tal não acontece com Simmel que tem a oportunidade de colocar sobre uma plataforma microscópica, três anos antes do rebentar da primeira Guerra Mundial, aquilo a que chama de "situação problemática típica do moderno ser humano" (ibid., 216), a saber,

o sentimento de estar rodeado por um sem-número de elementos culturais, que para ele não são desprovidos de significado, mas na sua maior profundidade tão-pouco possuem significado; que enquanto massa têm algo de opressivo, uma vez que ele não pode assimilar todos os aspectos singulares, porém tão-pouco pode simplesmente rejeitar esse todo, uma vez que por assim dizer ele pertence potencialmente à esfera do seu desenvolvimento cultural (ibid.).

Semelhante constatação traça-nos o perfil desse "moderno nervosismo" de que já falava Freud e que transcende amplamente o fundamento freudiano da sexualidade para evidenciar uma estrutura dissipativa, diríamos: mais indisponivel do que propriamente inapta para detectar correlações e tecer fios narrativos. Nesta longa citação de Simmel vemos in nuce potenciais formas de degeneração cultural, no sentido da multiplicação de cultura mas funcionalizados ou meramente reprodutivos. O que nos parece sobretudo problemática é a discrepância entre um glorificado sujeito epistémico e a incapacidade para fazer acompanhar o evidente fascínio pelos estímulos culturais com um paciente trabalho reflexivo, crítico e autocrítico, reconhecedor dos elementos trágicos sem contudo os assimilar a não ser com acompanhamento crítico e distanciado e nunca em escala desencadeadora de catástrofes - de certo modo, de forma comparável à inoculação schilleriana.

O que em Nietzsche e Benjamin se traduz por um encantamento face aos detalhes do mundo real equivale igualmente a uma aceitação de todo o seu potencial trágico, numa atitude anti-reducionista que dispensa qualquer exigência ou tentativa de síntese. A postura tanto de Nietzsche como de Benjamin subtrai-se à análise de Simmel, também pela indiferença que ambos manifestam face ao que Simmel apelida de "reprodutibilidade arbitrária dos conteúdos do espírito objectivo" (ibid., 218). Tanto a força plástica nietzscheana como as imagens do pensamento benjaminianas parecem deleitar-se numa plenitude micro-histórica que deixa fluir, de certo modo como um curso de água numa paisagem, esse fio narrativo capaz de relativizar no tempo as potencialidades do trágico sem as anular, bem como de atravessar o núcleo duro da tragédia, porém sobrevivendo-lhe.

Os três autores em questão reconheceram, no dizer de J. Guilherme 
Merquior, essa verdade profunda do trágico que não se esgota na denúncia de uma ruptura mas vai mais além a ponto de "sentir que a ruptura pertence como tal à lei das coisas" (Merquior, 1969: 232). A análise de Simmel pode ainda ser considerada como um sismógrafo pressentindo a catástrofe inerente à amálgama forçada desses elementos heterogéneos que, deixados no diferimento espácio-temporal resultante da respectiva dinâmica, podem abrir novos horizontes de percepção - e por aí de conceptualização.

Por seu turno, o mesmo Benjamin que não esconde a sua nostalgia face à perda da aura da obra de arte na era da reprodutibilidade técnica é esse ser reconciliado com as coisas irresolvidas, de forma diferenciada. Isto porque é precisamente a reprodutibilidade que permite, como sabemos, uma forma de acesso indirecto à obra original, cuja representação insuficiente através da reprodução é aceite como uma das muitas regras de um jogo que sempre se soube não se poder dominar. Não são tanto as sempre insuficientes imitações, mas sobretudo as traduções e interpretações da arte que não só resgatam memórias mas também recompõem todo o tecido de luz e sombra que perfaz qualquer figuração cultural.

Com Benjamin, não precisamos de evocar os clássicos para assistirmos a um "comportamento narrativo" que parece querer recuperar novas formas de "comunicabilidade e sagesse" (ibid., 126), em todo o caso anteriores ou alheias à obsessão messiânica que se lhe tornou funesta sob o agravamento dos condicionalismos da II Guerra Mundial. Atenda-se às pequenas narrativas imagéticas da Einbahnstrasse (Rua de Sentido único), às Denkbilder (Imagens do Pensamento) em que não só cada esquina de uma cidade mas igualmente cada ruga da pessoa amada albergam biografias condensadas e potenciais destinos trágicos. Mas também sabemos como o seu agudo sentido da itinerância do trágico se viu submerso pela fatal sequência de condições precárias em que se encontrou nos últimos meses de vida. Se o acumular de informação sobre o fim de Benjamin pode fazer com que este em tudo se assemelhe a uma morte anunciada, se a leitura das Teses sobre o conceito de História agrava essa tendência de precipitação cumulativa com a obsessão messiânica, convém também recordar o esforço que o autor fazia para contrariar toda a densificação trágica, como o demonstram certas passagens da sua correspondência. Em 11 de Janeiro de 1940, Benjamin escreve, ainda de Paris, a Gershom Scholem que já havia emigrado para a Palestina: "Cada linha que podemos hoje fazer com que seja publicada é - tão incerto é o futuro ao qual a legamos - uma vitória arrancada aos poderes da escuridão" (Benjamin, 1978: 846). Mais adiante, evoca as "manifestações do espírito da época" que teria colocado na paisagem desértica desses dias "certas marcas impossíveis de não serem reconhecidas por beduínos como nós" (ibid.). Mais adiante ainda, interroga-se sobre 
os eventuais benefícios da distância, na medida em que ela transformaria disputas acaloradas num sentimento de pertença longínquo (cf. ibid.).

A imagem do deserto e das suas tempestades de areia é usada por $\mathrm{H}$. Arendt para significar, evocando Nietzsche, um ambiente hostil a que as pessoas não sobreviveriam sem oásis (Arendt, 2007: 167s). A tempestade de areia seria o sistema totalitário que tudo destrói à sua passagem, trucidando também na sua voragem a purificação catártica, a clarividência trágica. A reacção a essa tempestade de areia só poderia assemelhar-se à do anjo retratado no seu horror às consequências do progresso, na nona tese sobre o conceito de História.

Poderemos dizer ainda que Benjamin sucumbiu a uma sobrecarga de capacidade para a leitura dos sinais trágicos da História? E contudo é Hannah Arendt que nos lembra que só naquele dia fatal de 26 de Setembro de 1940, quando os refugiados tinham ainda a ilusão de convencer a Guardia Civil espanhola a deixá-los atravessar o país sem o visto da saída da França, e antes de o penoso caminho dos Pirenéus se ver suspenso ao saber-se das exigências e do fecho da fronteira por parte dos representantes da Espanha franquista, que se tornou possível a catástrofe, culminando no suicídio do autor (cf. Arendt, 1991: 198s).

Façamos então um ponto da situação. Na perspectiva aqui defendida, a contemporaneidade não deve ser circunscrita a uma concepção simplistamente lúdica e hedonista num mundo globalizado, mas sim igualmente aferida mediante situações de precipitação de catástrofe, motivadas por uma obsessão de síntese após experiências de ruptura tidas por insolúveis. Os Leitmotive da crença no progresso, do deslumbramento técnico, e da subsequente disforia céptica, deixam entrever a dimensão de um "antropocentrismo autoritário" (Merquior, 1969: 169) inerente a todo o humanismo que tenta o impossível, a saber: fixar numa figuração estável a contingência das relações humanas, um pouco à imagem e semelhança das ciências sociais que encerram em grelhas estatísticas e esbatem em tendências globalizantes essa instância precária que é o ser humano. Ora este respira numa atmosfera carregada de memória e palpita nas membranas do tecido trágico.

Reconhecer os pontos nevrálgicos deste mesmo tecido equivale assim a discernir, não sem ironia, como a história se repete na sua contingência e como é precária e insuficiente, mas nem por isso menos necessária, qualquer precaução reflexiva enquanto aprendizagem do reconhecimento dos sinais de tragédia. Porque esta surge ora com aparente imprevisibilidade, ora com o fascínio de uma irresistível inevitabilidade. 
Actualmente, a rapidez dos códigos de comunicação digital tende a curto-circuitar, e por aí a neutralizar ainda mais, toda a reflexividade que poderia servir de bússola clarividente em terrenos minados por sinais do trágico. Este só se torna insustentável na medida em que é voluntaristamente escamoteado ora por indivíduos singulares que se arriscam a permanecer à mercê da clivagem entre a glorificação do sujeito epistémico e o constrangimento circunstancial ao exercício da vontade livre, ora por poderes autoritativos que, perseguindo ideologias autistas, precipitam a ocorrência de crises.

Quantas oportunidades têm sido perdidas de fazer passar o fio narrativo nessa clivagem denunciada por Simmel, que porém tão pouco disfarça uma nostalgia de grandes sínteses, mesmo sabendo-as inatingíveis ou muito mais grave - demasiado acessíveis e de consequências previsíveis na dobra de jogos de poder político, financeiro, militar ou mediático?

Resta-nos reaprender com estes três autores a auscultar as advertências do trágico, para depois as rearticular e recombinar, transpondo limites quantas vezes for necessário para seguir as exigências de uma consciência trágica, liberta do lastro reactivo de uma culpabilidade que nada mais é do que uma carga ideológica regressiva - como Nietzsche bem o sabia - e por aí desejavelmente reconvertível para um sentido de responsabilidade prospectiva. Só esta, liberta desse mesmo lastro que também obnubila qualquer forma de clarividência, torna o trágico não só sustentável como indispensável, sem precisar de renunciar a uma dimensão lúdica proporcionada pelo fio condutor da narratividade. 


\section{BIBLIOGRAFIA}

Arendt, Hannah (1991), Homens em Tempos Sombrios. Lisboa: Relógio d'Água.

- (2007), A Promessa da Política. Lisboa: Relógio d’Água.

Benjamin, Walter (1978), Briefe. Herausgegeben und mit Anmerkungen versehen von Gershom Scholem und Theodor W. Adorno. Frankfurt am Main: Suhrkamp (2 vols.).

- (1980), Gesammelte Schriften. Unter Mitwirkung von Theodor W. Adorno und Gershom Scholem herausgegeben von Rolf Tiedemann und Hermann Schweppenhäuser. Frankfurt am Main: Suhrkamp (12 vols.).

- (2004), Imagens do Pensamento. Obras escolhidas de Walter Benjamin. Edição e tradução de João Barrento. Lisboa: Assírio \& Alvim.

Merquior, José Guilherme (1969), Arte e Sociedade em Marcuse, Adorno e Benjamin. Rio de Janeiro: Tempo Brasileiro.

Nietzsche, Friedrich (1988), Kritische Studienausgabe. Herausgegeben von Giorgio Colli und Mazzino Montinari. München: dtv (referida no corpo do texto com os respectivos números do volume e da página).

Schiller, Friedrich (1997), "Sobre o Sublime" (1802), in: Textos sobre o Belo, o Sublime e o Trágico. Tradução, introdução, comentário e glossário de Teresa Rodrigues Cadete. Lisboa: INCM, pp. 217-230).

Simmel, Georg (1986), Philosophische Kultur. Über das Abenteuer, die Geschlechter und die Krise der Moderne. Berlin: Wagenbach. 


\begin{abstract}
RESUMO
O presente estudo pretende demonstrar o modo como as análises de Nietzsche, Simmel e Benjamin sobre o fenómeno trágico podem ensinar-nos a cultivar o tecido trágico e a conviver com o solo sistémico que o alimenta, a fim de criar capacidades para atravessar os núcleos ou ocorrências trágicas e transformar posteriormente as respectivas memórias em formas de narratividade, articuladas num fio sequencial. As deformações de perspectiva da modernidade (razão funcional, autoritarismo, antropocentrismo), impostas pelas contingências das sociedades actuais, vêem-se assim criticamente compensadas pelo entendimento do fundamento trágico inerente à existência humana.
\end{abstract}

Palavras-chave: tecido trágico - núcleo trágico - inoculação - fio narrativo

\begin{abstract}
The present study aims to demonstrate how the analyses by Nietzsche, Simmel and Benjamin of the tragic phenomenon may teach us how to cultivate the tragic fabric and to live with the systemic soil that nourishes it, in order to create abilities to cross over the cores or tragic occurrences and to transform afterwards the respective memories into forms of narrativity, articulated in a sequence thread. The perspective deformations of modernity (functional reason, authoritarianism, anthropocentrism), imposed by the contingency of the present societies, may be in this way critically compensated by the understanding of the tragic fundament that is inherent to human existence.
\end{abstract}

Key-words: tragic fabric - tragic core - inoculation - narrative thread 